\title{
ESTABILIDADE FENOTÍPICA DE LINHAGENS DE FEIJOEIRO EM TRÊS ÉPOCAS DE PLANTIO NO ESTADO DE SÃO PAULO ${ }^{1}$
}

\author{
SÉRGIO AUGUSTO MORAIS CARBONELL² e ANTÔNIO SIDNEY POMPEU²
}

\begin{abstract}
RESUMO - Com o objetivo de conhecer o comportamento de linhagens de feijoeiro nas três épocas tradicionais de plantio do Estado de São Paulo, com base em dados de estabilidade fenotípica, dois grupos de experimentos foram instalados nas épocas das águas (setembro-outubro), da seca (janeiro-fevereiro) e de inverno (maio-junho). O grupo 1 (G1), com 47 experimentos, foi formado por 16 linhagens e o controle, cultivar Carioca 80SH, e o grupo 2 (G2), com 44 experimentos, formado por 11 linhagens e pelos controles, cultivares Carioca $80 \mathrm{SH}$ e Rosinha $\mathrm{G}_{2}$. O delineamento experimental foi o de blocos ao acaso, com cinco repetições e parcelas constituídas de uma linha de $5 \mathrm{~m}$ de comprimento. As análises de variância das produções de grãos foram realizadas por experimento dentro de cada grupo (G1/G2) e conjunta (geral e por época de plantio). Os parâmetros de estabilidade foram estimados pelo método proposto por Cruz et al. (1989). Foram observadas várias linhagens adaptadas em ambientes desfavoráveis em pelo menos uma época de plantio. Diversos genótipos comportaram-se como responsivos ou estáveis nos dois conjuntos de experimentos. Os resultados sugerem a possibilidade de direcionar a recomendação de cultivares, com a escolha das linhagens mais adaptadas e responsivas, específicas para as épocas de cultivo.
\end{abstract}

Termos para indexação: Phaseolus vulgaris, adaptabilidade, recomendação de cultivares, produtividade.

\section{PHENOTYPICAL STABILITY OF COMMON BEAN LINES IN THREE GROWING SEASONS IN SÃO PAULO STATE, BRAZIL}

\begin{abstract}
Aiming at knowing the yield potential behavior of selected common bean lines based on data of phenotypical stability, two experimental sets were carried out in the three traditional growing seasons: rainy (September-October), dry (January-February) and winter (May-June). The first set, with 47 trials, was made up of 16 experimental lines and the check Carioca 80SH cultivar; the second, with 44 trials, was made up of 11 lines and the checks Carioca $80 \mathrm{SH}$ and Rosinha $\mathrm{G}_{2}$ cultivars, allocated to the three growing seasons above cited. The experimental design was a randomized complete block with five replications and plots constituted of a line of $5 \mathrm{~m}$ of length. Joint (general and seasonal) and single (per season) statistical analyses were performed on the yield data. Phenotypical stability and responsiveness were estimated by Cruz et al. (1989). Several adapted lines in unfavorable environments were observed in at least a growing season. Several genotypes showed high responsiveness or stability. The results indicated the feasibility of recommending cultivars through the selection of the best adapted and responsive experimental lines, specific for each growing season.

Index terms: Phaseolus vulgaris, adaptability, grain production, recommendation of cultivar.
\end{abstract}

\footnotetext{
${ }^{1}$ Aceito para publicação em 19 de fevereiro de 1999.

${ }^{2}$ Eng. Agrôn., Dr., Seção de Genética, Instituto Agronômico, Caixa Postal 28, CEP 13001-970 Campinas, SP. Bolsista do CNPq. E-mail: carbonel@cec.iac.br
}

\section{INTRODUÇÃO}

O feijoeiro (Phaseolus vulgaris) é cultivado, atualmente, no Estado de São Paulo, em três 
épocas: das águas, da seca e de inverno, com os plantios efetuados nos meses agosto-outubro, janeiro-março e abril-maio, respectivamente. Nessas épocas, os locais ou regiões mais adequados para o plantio foram determinados de acordo com o zoneamento ecológico, levando-se em consideração principalmente o déficit hídrico e a temperatura (Pizan et al., 1994).

Como nessas épocas de cultivo as condições climáticas diferem, propiciando o aparecimento de diferentes patógenos ou de suas raças, há necessidade de se conhecer o comportamento de linhagens obtidas dentro do programa de melhoramento desenvolvido para o Estado. Essa avaliação é importantíssima para o conhecimento da adaptação das linhagens a determinado ambiente e da sua estabilidade de produção ao longo dos anos e épocas de plantio. Estudos dessa natureza têm demonstrado a significância da interação genótipo $\mathrm{x}$ ambiente e conseqüentemente o comportamento diferencial das linhagens nos anos e épocas estudados (Ramalho et al., 1993). Os municípios de instalação de experimentos também são importantes no comportamento fenotípico das linhagens, dadas as condições edafoclimáticas diferentes, que possibilitam a definição de locais estratégicos para instalação desses ensaios com vistas a recomendação de cultivares (Duarte \& Zimmermann, 1991). Com base nestes conceitos de avaliação do desempenho em locais estratégicos e nos parâmetros de estabilidade fenotípica de cultivares, foi possível a Abreu et al. (1992) definirem linhagens promissoras de feijoeiro para o Estado de Minas Gerais. Miranda et al. (1993), também com base em dados de estabilidade e adaptabilidade de genótipos, sugerem a recomendação de cultivares para a Zona da Mata de Minas Gerais e indicam as melhores épocas de cultivo para esses genótipos.

Este trabalho teve por objetivo avaliar o comportamento das linhagens desenvolvidas no Instituto Agronômico, com base nos dados de estabilidade fenotípica nas três épocas de plantio, em vários locais e anos.

\section{MATERIAL E MÉTODOS}

Dois grupos de experimentos foram instalados no período de 1990 a 1993, nas três épocas de plantio (águas, seca e inverno), nas principais regiões produtoras de feijão do Estado de São Paulo. O grupo 1 (G1), formado pelas linhagens $51-1-1-1,60-1,6-51,62-10$, 8-3-12, Gen 2-1-2-10, Gen 2-1-4-1-2-8, Gen 2-1-5-4-9-1, H3886-50, H4886-50, H85125-54-3-3, H85125-51-2-1,6-1, H8515-52, H853-50, H853-50-2, H853-50-6, H8557-54 e pela cultivar Carioca $80 \mathrm{SH}$, totalizou 47 experimentos, sendo 13, 17 e 17, distribuídos, respectivamente, nas épocas das águas, seca e inverno. O grupo 2 (G2), constituído pelas linhagens 4-1-2-2-1,4-1-1, 51, 52-2-6, 60-4-7, H3886-52, H5886-52, H5886-54, H5986-52, H5986-53, H8522-50-2 e pelas cultivares Carioca $80 \mathrm{SH}$ e Rosinha $\mathrm{G}_{2}$, resultou em 44 experimentos sendo 13, 16 e 15, nos plantios das águas, seca e inverno, respectivamente. Este agrupamento das linhagens (G1 e G2) foi baseado em avaliações realizadas em experimentos preliminares realizados durante os anos de 1988 e 1989 , nos municípios de Campinas, Votuporanga e Ribeirão Preto. Estas avaliações incluíram dados de produção de grãos, cor e formato da semente e reação aos patógenos da antracnose, mancha-angular, mosaico-comum, mosaico-dourado, crestamento bacteriano comum, e ferrugem.

O delineamento experimental utilizado foi o de blocos casualizados, com cinco repetições. A parcela experimental foi constituída de uma linha de $5 \mathrm{~m}$ de comprimento, com espaçamento entre fileiras de $0,60 \mathrm{~m}$ para a época de inverno e 0,50 m para águas e seca, e de 0,20 m na linha, com três sementes por cova, para, no desbaste, deixar duas plantas por cova ou 50 por linha. A adubação usada nestes experimentos foi de $430 \mathrm{~kg} / \mathrm{ha}$ da fórmula 4-14-8 no plantio e $65 \mathrm{~kg} / \mathrm{ha}$ de sulfato de amônio em cobertura. Foram realizadas pulverizações para o controle de agentes patogênicos e insetos, usando-se uma mistura de paration metil, mevinfos e manzate, na proporção $2 \mathrm{~cm}^{3}: 2 \mathrm{~cm}^{3}: 2 \mathrm{~g} /$ litro. Nos plantios das águas e da seca, a semeadura foi realizada em condições de umidade propícias para a germinação e emergência das plântulas. No cultivo de inverno, usou-se irrigação através dos sistemas convencional e pivô central ou através da elevação do lençol freático, sistema pôlder, em todas as fases de desenvolvimento da cultura.

As plantas das parcelas, após atingirem a maturação, foram colhidas e postas em sacos de algodão, para efetuar a trilha através da batida com galhos. Após a limpeza os grãos foram pesados.

As análises de variância foram realizadas por experimento dentro de cada grupo (G1 e G2) e, posterior- 
mente, os experimentos foram analisados em conjunto (geral e por época de plantio) (Pimentel-Gomes, 1985). A análise de estabilidade utilizada foi baseada no método proposto por Cruz et al. (1989). Nesse método se procura genótipos produtivos, estáveis em ambientes desfavoráveis $\left(b_{1} \leq 1\right)$, e muito responsivos em ambientes favoráveis $\left(b_{1}+b_{2} \geq 1\right)$.

\section{RESULTADOS E DISCUSSÃO}

A análise de variância conjunta e por época mostrou efeitos significativos quanto a genótipo, ambiente e quanto à interação genótipo x ambiente, nos dois conjuntos de experimentos. Este fato era esperado, já que os genótipos em estudo foram originários de diferentes cruzamentos e, embora tenham sido selecionados nas mesmas condições (Campinas, Votuporanga e Ribeirão Preto), quando avaliados em maior número de condições edafoclimáticas, que afetam sua fisiologia de desenvolvimento e de produção, há uma diferenciação natural em sua eficiência de produção.

A interação genótipo $\mathrm{x}$ ambiente, significativa na análise conjunta geral e conjunta por época, indica uma grande influência do ambiente no comportamento dos genótipos, mesmo quando comparados em uma mesma época de cultivo, em diferentes anos e locais. Estas diferenças podem ser atribuídas, em grande parte, à ocorrência de estresses (diferentes patógenos ou raças do mesmo patógeno, seca, diferença de fertilidade do solo) entre os locais escolhidos para compor cada época de plantio.

A produtividade média de grãos $(1.926 \mathrm{~kg} / \mathrm{ha})$ dos genótipos que compuseram o G1 foi maior que a produtividade média $(1.844 \mathrm{~kg} / \mathrm{ha})$ dos genótipos que compuseram o G2. Observou-se, ainda, que a produtividade média de grãos na época da seca (1.648 e $1.594 \mathrm{~kg} / \mathrm{ha}$, para G1 e G2) foi inferior em aproximadamente $20 \%$ às épocas de inverno $(2.094 \mathrm{e} 1.966 \mathrm{~kg} / \mathrm{ha})$ e das águas $(2.024 \mathrm{e}$ $2.013 \mathrm{~kg} / \mathrm{ha})$. Provavelmente, estes valores menores na época da seca devem-se à irregularidade de chuvas observada nesta época, onde pequenos períodos de estiagem podem afetar a produção de grãos. As maiores produtividades de grãos obtidas no Estado de São Paulo nas épocas das águas e de inverno devem-se, provavelmente, à ocorrência de chu- vas bem distribuídas durante todo o ciclo da cultura na época das águas, e à irrigação artificial no inverno. No entanto, isto não é regra, pois chuvas bem distribuídas na época da seca podem promover alta produtividade, semelhante ou maior que a das épocas das águas e de inverno. Os coeficientes de variação observados nestes experimentos foram inferiores a $20 \%$. O coeficiente de determinação experimental, observado em análises de variância conjunta (geral e por época) no G1 e G2, foi considerado alto, ou seja, acima de $80 \%$ em todas as análises.

Observando as produções médias de todos os ensaios (Tabela 1) do G1, verificou-se que algumas linhagens tiveram médias de produtividade de grãos acima do padrão utilizado, 'Carioca $80 \mathrm{SH}^{\prime}$ (1.990 kg/ha), com destaque para H853-50-2, H853-50 e H853-50-6, todas com grão tipo carioca, além de 51-1-1-1, de grãos pretos. No G2, as médias mais elevadas foram das linhagens H5986-52, H5986-53 e H5986-50, de sementes do tipo rosinha e H8522-50-2, do tipo carioca. Neste grupo, observou-se produtividade de 1.946 e $1.731 \mathrm{~kg} / \mathrm{ha}$ nos controles 'Carioca 80SH' e 'Rosinha $\mathrm{G}_{2}$ ', respectivamente. As médias destas linhagens são consideradas altas, dada a heterogeneidade de condições (ambiente) em que estas produções foram obtidas, podendo atingir valores maiores em ambientes favoráveis, como observado na Tabela 1 . Tais produtividades, aliadas a valores de adaptabilidade em ambientes desfavoráveis $\left(b_{1}<1\right)$, responsividade $\left(b_{1}+b_{2} \geq 1\right)$ e estabilidade ( $Q M$ desvio $\left.<1\right)$, são características importantes de reunir em um genótipo para fins de recomendação de cultivo regional ou estadual.

Observou-se (Tabela 1) que as estimativas de adaptabilidade $\left(b_{1}\right)$ variaram de 0,78 a 1,20 e de 0,79 a 1,26 nos conjuntos G1 e G2 de experimentos respectivamente. As linhagens H853-50-2 e H853-50-6 mostraram valores $b_{1}$ de 0,78 e 0,86 , significativos a $1 \%$, sendo portanto as mais adaptadas (produtivas) a ambientes desfavoráveis no grupo G1. Além dessas linhagens, observaram-se valores significativos a $5 \%$ nas linhagens H853-50 e H85125-51-2-1,6-1, com valores de 0,89 e de 0,91 . Nesse grupo, a cultivar Carioca $80 \mathrm{SH}$ e as linhagens Gen 2-1-4-1-2-8, 8-3-12, H3886-50, H8557-54 e 62-10 com valores $b_{1}$ de 1,20, 1,14 e 1,12 


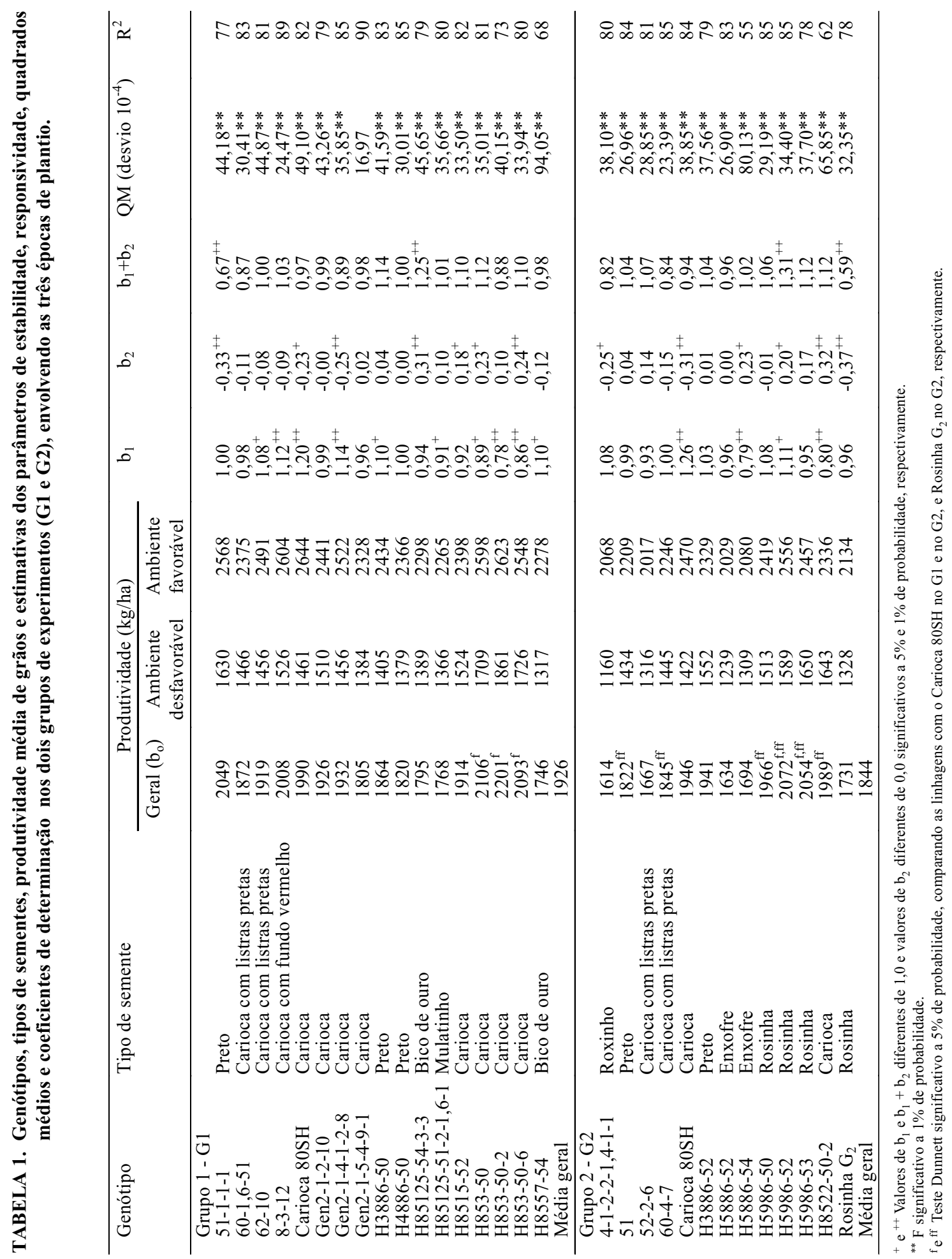

Pesq. agropec. bras., Brasília, v.35, n.2, p.321-329, fev. 2000 
( $\operatorname{significativos~a~} 1 \%$ ) e de $1,10,1,10$ e 1,08 (significativos a 5\%), foram consideradas as menos adaptadas (produtivas) a ambientes desfavoráveis, respectivamente. No G2, as melhores linhagens quanto à adaptação e à maior produção de grãos em situações desfavoráveis, foram H5886-54 e H8522-50-2, com valores $b_{1}$ de 0,79 e 0,80 significativos a $1 \%$, sendo as cultivares Carioca $80 \mathrm{SH}\left(\mathrm{b}_{1}=1,26\right.$, significativo a 1\%) e H5986-52 ( $b_{1}=1,11$, significativo a 5\%) as menos adaptadas. As demais linhagens, com valores de $b_{1}$ não diferentes de 1 , também são consideradas linhagens adaptadas, tendo comportamento semelhante nos ambientes desfavoráveis.

A estimativa de $b_{2}>0$ indica que determinado genótipo responde à aplicação de insumos ou à melhoria do ambiente. Deste modo, valores negativos são indesejáveis e contribuem para redução dos valores de $b_{1}+b_{2}$, sendo observados valores de 1,25 a 0,67 no G1 e de 1,31 a 0,59 no G2 (Tabela 1 ). Com exceção da linhagem 51-1-1-1 $\left(b_{1}+b_{2}=0,67\right.$, significativo a $1 \%$ ) no $\mathrm{G} 1$ e da cultivar Rosinha $\mathrm{G}_{2}$ $\left(b_{1}+b_{2}=0,59\right.$, significativo a $\left.1 \%\right)$ no $G 2$, todos os demais genótipos apresentaram valores de $b_{1}+b_{2} \geq 1$, mostrando serem responsivos à melhoria do ambiente. Isto deve-se, provavelmente, às condições nas quais as populações que deram origem às linhagens avaliadas no G1 e G2 foram conduzidas e selecionadas, em ambientes considerados favoráveis do ponto de vista de solo, época de cultivo, e suprimento de água. Deste modo, essas linhagens podem ser classificadas, genericamente, como exigentes em condições ambientais, manifestando seu potencial genético sob estas condições. Ambientes considerados marginais de cultivo (fertilidade baixa do solo e baixo nível de tecnologia aplicada no cultivo) podem, muitas vezes, levar a baixas produções de grãos destas linhagens.

Observou-se também a pouca previsibilidade do comportamento (Quadrado médio - QM desvio) das linhagens que compõem o G1 e o G2 (Tabela 1), estimativa que avalia a estabilidade dos genótipos, com exceção da linhagem Gen2-1-5-4-9-1 no G1 e de 60-4-7 no G2, o que era esperado, em face da heterogeneidade de ambientes ocasionada por diferenças de anos, épocas de plantio e locais. No entanto, o coeficiente de determinação próximo e aci- ma de $80 \%$, obtido na maioria das linhagens, reduz a imprevisibilidade, mostrada pelo QM desvio, e assegura a eficiência do método em explicar a variação nos dados observados em cada genótipo avaliado.

No conjunto G1 (Tabela 2), as maiores produções médias no cultivo das águas foram observadas nas linhagens H853-50-2 (2.274 kg/ha), 8-3-12 (2.262 kg/ha) e H853-50-6 (2.200 kg/ha), com a 'Carioca $80 \mathrm{SH}$ ' atingindo $2.165 \mathrm{~kg} / \mathrm{ha}$. Das linhagens estudadas nessa época, H3886-50 ( $b_{1}=0,81$, significativo a $5 \%$ ) foi a mais adaptada aos ambientes desfavoráveis, enquanto H85125-54-3-3 $\left(b_{1}=1,27\right.$, significativo a $1 \%)$ e H853-50 ( $b_{1}=1,18$, significativo a $1 \%$ ) foram as menos adaptadas. No caso da responsividade e melhoria do ambiente, foi observada a maior estimativa na linhagem H8515-52 $\left(\mathrm{b}_{1}+\mathrm{b}_{2}=1,42\right.$, significativo a $\left.5 \%\right)$, e na 'Carioca $80 \mathrm{SH}^{\prime}\left(\mathrm{b}_{1}+\mathrm{b}_{2}=0,53\right.$, significativo a $\left.1 \%\right)$ e Gen 2-1-4-1-2-8 $\left(b_{1}+b_{2}=0,60\right.$, significativo a $5 \%$ ), os menores valores.

No G2, as melhores produções médias de grãos foram obtidas pelos genótipos H5986-53 (2.255 kg/ha), 'Carioca 80SH' (2.235 kg/ha), H5986-52 ( $2.225 \mathrm{~kg} / \mathrm{ha}$ ) e H5986-50 (2.221 kg/ha). Os genótipos mais adaptados aos ambientes desfavoráveis foram

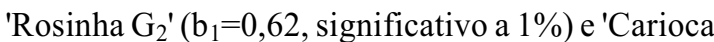
$80 \mathrm{SH}^{\prime}\left(\mathrm{b}_{1}=0,81\right.$, significativo a $5 \%$ ), e os menos adaptados, H5986-52 ( $b_{1}=1,29$, significativo a $\left.1 \%\right)$ e 51 $\left(b_{1}=1,23\right.$, significativo a 5\%). A linhagem 60-4-7 $\left(b_{1}+b_{2}=1,59\right.$, significativo a $\left.1 \%\right)$ destacou-se quanto à melhoria ambiental, e 'Rosinha $\mathrm{G}_{2}\left(\mathrm{~b}_{1}+\mathrm{b}_{2}=0,37\right.$, significativo a $1 \%)$ e 4-1-2-2-1,4-1-1 $\left(b_{1}+b_{2}=0,39\right.$, significativo a $1 \%$ ) os menos responsivos. Nessa época, não foram encontrados reunidos em um único genótipo valores ideais de estimativas de estabilidade (QM desvio/menores não-significativos), adaptabilidade aos ambientes desfavoráveis $\left(\mathrm{b}_{1}<1\right)$, responsividade à melhoria do ambiente $\left(b_{1}+b_{2} \geq 1\right) e$ produção de grãos (média superior ao padrão) para recomendação de cultivo nessa época. Deste modo, o valor da produção média de grãos é considerado a principal característica para recomendação, aliada às observações de coloração do grão e resistência a doenças. 


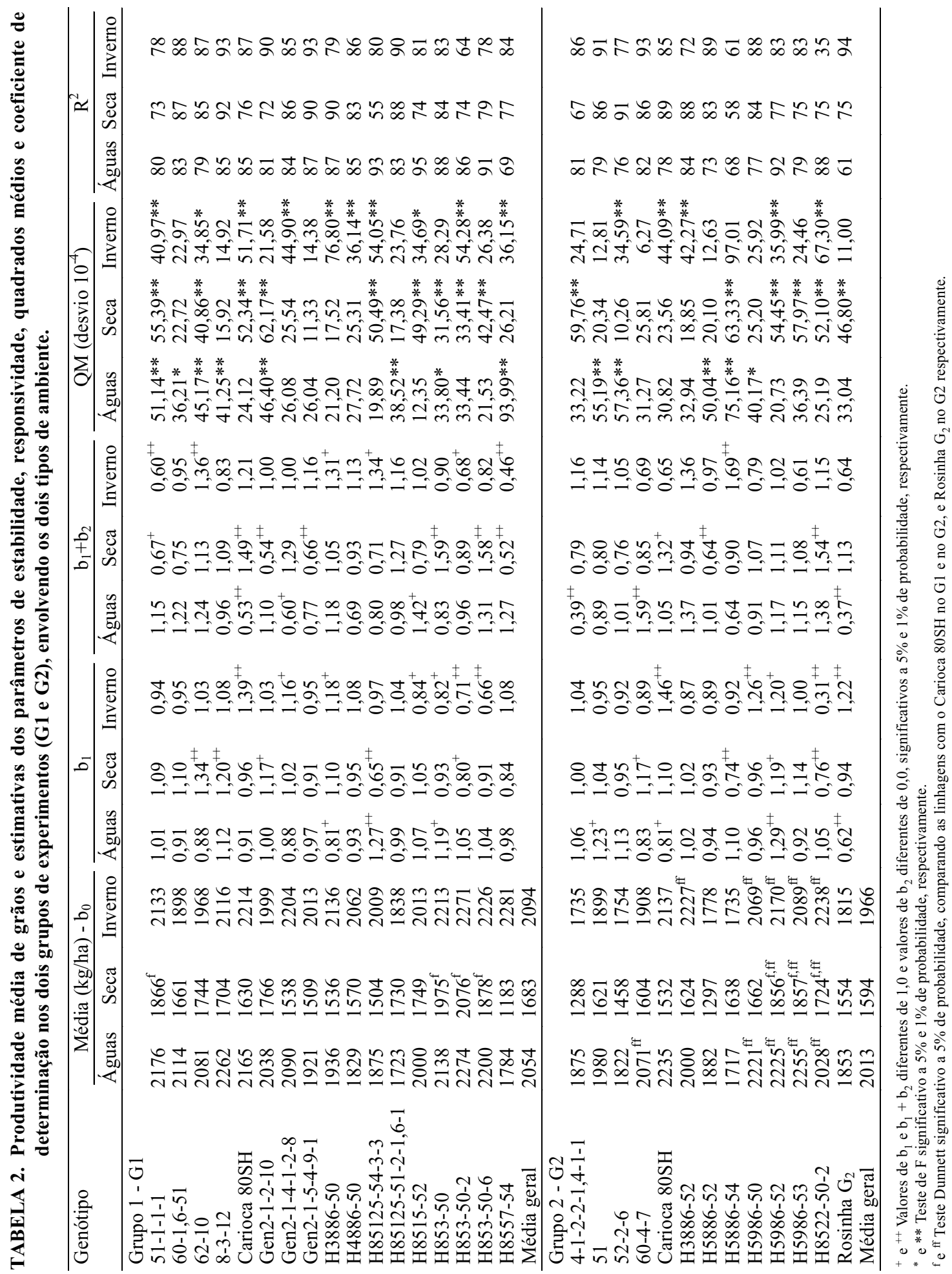


$\mathrm{Na}$ época da seca (grupo G1), as produções médias mais elevadas foram das linhagens H853-50-2 (2.076 kg/ha), H853-50 (1.975 kg/ha), H853-50-6 (1.878 kg/ha) e 51-1-1-1 (1.866 kg/ha), com a 'Carioca' $80 \mathrm{SH}$ obtendo $1.630 \mathrm{~kg} / \mathrm{ha}$. As linhagens H85125-54-3-3 $\left(\mathrm{b}_{1}=0,65\right.$, significativo a $\left.1 \%\right)$ e H853-50-2 $\left(b_{1}=0,80\right.$, significativo a $\left.5 \%\right)$ foram as mais adaptadas aos ambientes desfavoráveis, enquanto as linhagens $62-10\left(b_{1}=1,34\right.$, significativo a $1 \%), 8-3-12\left(b_{1}=1,20\right.$, significativo a $\left.1 \%\right)$ e Gen 2-1-2-10 $\left(b_{1}=1,17\right.$, significativo a $\left.5 \%\right)$, as menos adaptadas. Quanto à responsividade à melhoria do ambiente, destacaram-se H853-50 $\left(b_{1}+b_{2}=1,59\right.$, significativo a $\left.1 \%\right)$, HG853-50-6 $\left(\mathrm{b}_{1}+\mathrm{b}_{2}=1,58\right.$, significativo a $\left.1 \%\right)$ e 'Carioca $80 \mathrm{SH}^{\prime}$ $\left(b_{1}+b_{2}=1,49\right.$, significativo a $\left.1 \%\right)$. As menos responsivas foram $\mathrm{H} 8557-54 \quad\left(\mathrm{~b}_{1}+\mathrm{b}_{2}=0,52\right.$, significativo a $1 \%)$, Gen $2-1-2-10\left(b_{1}+b_{2}=0,54\right.$, significativo a $1 \%)$, Gen 2-1-5-4-9-1 $\left(b_{1}+b_{2}=0,66\right.$, significativo a $1 \%)$ e $51-1-1-1\left(b_{1}+b_{2}=0,67\right.$, significativo a $\left.5 \%\right)$.

No grupo G2, as maiores produções médias de grãos foram das linhagens H5986-53 (1.857 kg/ha) e H5986-52 (1.856 kg/ha), obtendo os controles 'Rosinha $\mathrm{G}_{2}$ ' e 'Carioca $80 \mathrm{SH}^{\prime} 1.554 \mathrm{~kg} / \mathrm{ha} \mathrm{e}$ $1.532 \mathrm{~kg} / \mathrm{ha}$, respectivamente. Os genótipos H5886-54 $\left(\mathrm{b}_{1}=0,74\right.$, significativo a $\left.1 \%\right)$ e H8522-50-2 $\left(b_{1}=0,76\right.$, significativo a $\left.1 \%\right)$ foram os mais adaptados e H5986-52 $\left(\mathrm{b}_{1}=1,19\right.$, significativo a $5 \%)$ e $60-4-7\left(b_{1}=1,17\right.$, significativo a $\left.5 \%\right)$ os menos adaptados, para os ambientes dessa época. Quanto à responsividade à melhoria ambiental, destacaram H8522-50-2 $\left(\mathrm{b}_{1}+\mathrm{b}_{2}=1,54\right.$, significativo a $1 \%$ ) e 'Carioca $80 \mathrm{SH}^{\prime}\left(\mathrm{b}_{1}+\mathrm{b}_{2}=1,32\right.$, significativo a $\left.5 \%\right)$, sendo H5886-52 $\left(b_{1}+b_{2}=0,64\right.$, significativo a $\left.1 \%\right)$ o menos responsivo. Nesta época, por apresentar os menores valores médios de produção de grãos, em vista, principalmente, da irregularidade das chuvas no período de cultivo, o valor de $\mathrm{b}_{1}$ é considerado tão importante quanto à produção de grãos para fins de recomendação, aliado a coloração do grão e resistência a doenças. Deste modo, as linhagens H853-50-6 no G1 e H8522-50-2 no G2 foram consideradas como promissoras de lançamento para cultivo pelo Instituto Agronômico. As linhagens H85125-54-3-3 no G1 e H5886-54 no G2 devido ao tipo de semente (coloração) foram colocadas em segundo plano para lançamento.
Quanto ao plantio de inverno, os destaques em G1 relativos a produções médias de grãos foram H8557-54 (2.281 kg/ha), H853-50-2 (2.271 kg/ha), H853-50-6 (2.226 kg/ha), 'Carioca $80 \mathrm{SH}^{\prime}$ $(2.214 \mathrm{~kg} / \mathrm{ha}), \mathrm{H} 853-50(2.213 \mathrm{~kg} / \mathrm{ha}) \mathrm{e}$ Gen 2-1-4-1-2-8 (2.204 kg/ha). As linhagens mais adaptadas foram $\mathrm{H} 853-50-6\left(\mathrm{~b}_{1}=0,66\right.$, significativo a $1 \%)$, H853-50-2 ( $b_{1}=0,71$, significativo a $\left.1 \%\right)$, H853-50 ( $b_{1}=0,82$, significativo a 5\%) e H8515-52 $\left(b_{1}=0,84\right.$, significativo a $5 \%$ ) e a 'Carioca $80 \mathrm{SH}^{\prime}$ $\left(b_{1}=1,39\right.$, significativo a $\left.1 \%\right), H 3886-50\left(b_{1}=1,18\right.$, significativo a 5\%) e Gen 2-1-4-1-2-8 ( $b_{1}=1,16$, significativo a $5 \%$ ), as menos adaptadas. Sobressaíram quanto à resposta à melhoria ambiental as linhagens $62-10\left(b_{1}+b_{2}=1,36\right.$, significativo a $\left.1 \%\right)$, H85125-54-3-3 $\left(b_{1}+b_{2}=1,34\right.$, significativo a 5\%) e H 3886-50 $\left(b_{1}+b_{2}=1,31\right.$, significativo a $\left.5 \%\right)$ enquanto H8557-54 $\left(b_{1}+b_{2}=0,46\right.$, significativo a $\left.1 \%\right), 51-1-1-1$ $\left(b_{1}+b_{2}=0,60\right.$, significativo a $1 \%$ ) e H853-50-2 $\left(b_{1}+b_{2}=0,68\right.$, significativo a $\left.5 \%\right)$ foram as menos responsivas.

No G2, sobressaíram por suas produções médias de grãos no plantio de inverno os genótipos H8522-50-2 (2.238 kg/ha), H3886-52 (2.227 kg/ha), H5986-52 (2.170 kg/ha) e 'Carioca $80 \mathrm{SH}^{\prime}$ $(2.137 \mathrm{~kg} / \mathrm{ha})$, sendo de $1.815 \mathrm{~kg} / \mathrm{ha}$ a observada em 'Rosinha $\mathrm{G}_{2}$ '. A linhagem H8522-50-2 $\left(\mathrm{b}_{1}=0,32\right.$, significativo a $1 \%$ ) destacou-se das demais por sua adaptabilidade, enquanto 'Carioca $80 \mathrm{SH}^{\prime}$ $\left(b_{1}=1,46\right.$, significativo a $\left.1 \%\right)$, H5986-50 $\left(b_{1}=1,26\right.$, significativo a $1 \%)$, 'Rosinha $\mathrm{G}_{2}{ }^{\prime}\left(\mathrm{b}_{1}=1,22\right.$, significativo a $1 \%)$ e H5986-52 ( $b_{1}=1,20$, significativo a $\left.5 \%\right)$, foram as menos adaptadas.

Em relação à responsividade, todas responderam bem à melhoria de ambiente, dentro do cultivo de inverno, com destaque para H5886-54 $\left(\mathrm{b}_{1}+\mathrm{b}_{2}=1,69\right.$, significativo a $1 \%$ ). Nesta época, o cultivo é realizado com o auxílio de irrigação artificial, e portanto, sob pressão apenas de doenças sobre a produtividade de grãos. Deste modo, o comportamento das linhagens pode ser considerado semelhante ao da época das águas, que possibilita a mais variada combinação das estimativas de estabilidade e adaptabilidade, sempre aliados às características de semente, de reação às doenças e à produtividade de grãos. Tais estimativas são consideradas como mais um parâmetro a ser utilizado durante o complexo ato de recomendação e lançamento de uma nova cultivar, 
pois uma avaliação per se dessas estimativas não justifica uma recomendação, mas auxilia nas tomadas de decisão, que muitas vezes são baseadas em observações mínimas do comportamento, no momento da escolha para recomendação de uma ou outra linhagem promissora.

Verificou-se que somente as linhagens Gen 2-1-5-4-9-1 no G1 e 60-4-7 no G2 não apresentaram os QM desvios significativos para todas as épocas avaliadas, o que indica serem linhagens com comportamento altamente previsíveis (estáveis), além de possuírem elevados $\mathrm{R}^{2}$ (Tabela 2). As demais linhagens apresentam valores não-significativos de QM desvio, em, pelo menos, uma época de cultivo, o que indica previsibilidade dependente da época, embora apresente, na maioria das vezes, alto coeficiente de determinação $\left(\mathrm{R}^{2}\right)$. A avaliação baseada somente em dados de estabilidade destas duas linhagens as capacitariam para recomendação nas três épocas de plantio no Estado; no entanto, devido à média de produtividade inferior a das outras linhagem em cada época de plantio e coloração da semente da 60-4-7 (carioca com listras pretas), estas linhagens não foram consideradas como promissoras de recomendação. Desse modo, estimativas de estabilidade, adaptabilidade e responsividade de linhagens e cultivares de feijoeiro, isoladamente, não podem ser determinantes do ato de recomendação por época de plantio ou geral (todas as épocas), mas sim como mais um parâmetro de avaliação das características do genótipo e sempre considerando uma produtividade superior à dos controles.

Observando o comportamento das linhagens nos grupos G1 e G2, nota-se que a maioria foi adaptada aos ambientes desfavoráveis, e responsivas à melhoria do ambiente em pelo menos uma das três épocas de cultivo. Este comportamento em relação à adaptabilidade e responsividade diferencial dos genótipos de acordo com a época de plantio, deve-se, provavelmente, no caso do feijoeiro, à presença ou ausência de patógenos, e, em alguns casos, de suas raças nas épocas de plantio (informações não publicadas). Apenas a linhagem H5986-52 (G2) não foi adaptada a nenhuma das épocas estudadas.
A estabilidade (QM desvio) observada na análise geral das épocas de plantio (Tabela 1) e no desdobramento da análise por época de plantio (Tabela 2) mostrou uma redução desses valores, e conseqüentemente, a eficiência do zoneamento ecológico da cultura na determinação dos locais (municípios) de cultivo por época determinado por Pizan et al. (1994).

Algumas das linhagens avaliadas, H853-50-2 (IAC-Carioca Pyatã), H853-50-6 (IAC-Carioca Akytã), H8522-50-2 (IAC-Carioca Aruã) e H3886-52 (IAC-Maravilha), por suas produções médias de grãos, reação resistente aos agentes patogênicos da antracnose e vírus-do-mosaicocomum, coloração de sementes e porte ereto de planta, já foram lançadas e recomendadas como novas cultivares (Pompeu, 1997). A linhagem 51-1-1-1, em mistura com sua irmã 51-1-1-2 (IAC-Una) e H8557-54 (IAC-Bico de Ouro), pelas características acima mencionadas e pela coloração das sementes, preta e tipo bico-de-ouro, respectivamente, também foram lançadas e recomendadas no Estado de São Paulo (Pompeu, 1997). No entanto, a linhagem H8557-54, por sua baixa produção na época da seca, foi recomendada somente para as épocas das águas e de inverno.

\section{CONCLUSÕES}

1. Várias linhagens são adaptadas a ambientes desfavoráveis em pelo menos uma época de plantio, com destaque para H853-50-2, H853-50-6 e H85125-51-2-1,6-1 (G1) e H5886-54 e H8522-50-2 (G2).

2. A linhagem H5986-52 (G2) não é adaptada a nenhuma das épocas estudadas.

3. Diversos genótipos comportam-se como responsivos à melhoria do ambiente, com destaques para H85125-54-3-3 (G1) e H5986-52 (G2).

4. Os genótipos 60-1,6-51, H4886-50, H85125-51-2-1,6-1, H8515-52 e H853-50-6 (G1) e 52-2-6, H3886-52, H5886-54, H5986-53 e H8522-50-2 (G2) são adaptados e responsivos.

5. É possível direcionar a recomendação de cultivares, com a escolha das linhagens mais adaptadas e responsivas por épocas de cultivo. 


\section{AGRADECIMENTOS}

Aos funcionários das estações experimentais do IAC e das cooperativas, e aos agricultores, pelo auxílio na instalação dos experimentos; à FAPESP e ao CNPq, pelo apoio financeiro ao programa de melhoramento de feijoeiro no Instituto Agronômico.

\section{REFERÊNCIAS}

ABREU, A.F.B.; RAMALHO, M.A.P.; SANTOS, J.B dos. Desempenho e estabilidade fenotípica de cultivares de feijão em algumas localidades do Estado de Minas Gerais no período de 1989-1991. Ciência e Prática, Lavras, v.16, n.1, p.18-24, jan./mar. 1992.

CRUZ, C.D.; TORRES, R.A. de; VENCOVSKY, R. An alternative approach to the stability analysis proposed by Silva e Barreto. Revista Brasileira de Genética, Ribeirão Preto, v.12, p.567-580, 1989.

DUARTE, J.B.; ZIMMERMANN, M.J. de. Selection of location for common bean (Phaseolus vulgaris L.) germplasm evaluation. Revista Brasileira de Genética, Ribeirão Preto, v.14, n.3, p.765-770, 1991.

MIRANDA, G.V.; VIEIRA, C.; CRUZ, C.D.; ARAÚJO, G.A.A. Adaptabilidade e estabilidade de comportamento de cultivares de feijão em quatro municípios da zona da mata de Minas Gerais. Revista Ceres, Viçosa, v.41, n.232, p.591-609, 1993.

PIMENTEL-GOMES, F. Curso de Estatística Experimental . 11.ed. São Paulo : Nobel, 1985. 466p.

PIZAN, N.R.; BULISANI, E.A.; BERTI, A.J. Feijão: zoneamento ecológico e épocas de semeadura para o Estado de São Paulo. Campinas : CATI, 1994. 19p. (CATI. Boletim técnico, 218).

POMPEU, A.S. IAC-Maravilha, IAC-Una, IAC-Carioca Pyatã, IAC-Carioca Aruã, IAC-Carioca Akytã e IAC-Bico de Ouro: novos cultivares de feijoeiro. Bragantia, Campinas, v.56, n.1, p.79-85, 1997.

RAMALHO, M.A.P.; ABREU, A.F.B.; RIGHETTO, G.U. Interação de cultivares de feijão por épocas de semeadura em diferentes localidades do Estado de Minas Gerais. Pesquisa Agropecuária Brasileira, Brasília, v.28, n.10, p.1183-1189, out. 1993. 